\title{
The Changing Role of Deans in Higher Education - From Leader to Manager
}

\author{
Eystein Arntzen \\ Faculty for Teacher Education, University College of Ostfold, Norway
}

Copyright $(2016$ by authors, all rights reserved. Authors agree that this article remains permanently open access under the terms of the Creative Commons Attribution License 4.0 International License

\begin{abstract}
During the latter decades new perspectives on academic leadership have emerged along with new ways of organizing the decision making structure. The image of academic leader as manager has slowly but steadily been diffused internationally. In addition to the structural changes in the system of higher education the idea of new public management has changed the way academic work is supposed to be managed, in favour of enhanced managerial control and high demands on academic staff. It is reasonable to assume that these changes within the higher educational institutions, along with changes in the relationship between the government and the higher educational institutions, has led to changes in the role of the leaders, both referring to the tasks leaders are supposed to solve and which responsibility and authority they have. In this paper I study how the role of deans in teacher education is influenced by those changes.
\end{abstract}

Keywords Role of Deans, Organizational Changes, Leadership, Management

\section{Introduction}

Higher education institutions have a long history, and are of central importance in economic, social and cultural development for countries everywhere. Throughout time, academic institutions have sought to respond to the demands of changing and evolving environmental conditions of society. On the other hand they have also been among the most stable institutions during the past centuries.

Higher education has a long tradition in emphasizing academic leadership. The influence of the distinguished professor was for a long time perhaps the most important characteristic of the European higher education system. While it is recognized that higher educational institutions are historically collegial organizations, it is also recognized that the collegial system needs to support accountability and institutional responsibility, or even be more managerial in order to face the challenges of the future.

During the latter decades, new perspectives on academic leadership have emerged along with new ways of organizing the decision making structure in higher education institutions. Thus, images of academic leaders as coordinators, coalition builders, or entrepreneurs have slowly but steadily been diffused internationally, and has had a wide impact on higher education. These new images of academic leaders have been supported by a new set of ideas on how the sector should be organized and led (Askling \& Stensaker, 2002).

In addition to the structural changes in the system of higher education the idea of new public management has changed the way academic work is supposed to be managed, in favour of enhanced managerial control and high demands on academic staff. New public management emphasizes that leadership is vital in achieving organizational objectives and promoting organizational change. The normative elements in the new public management rhetoric are quite strong, emphasizing ideals rather than realities, simplicity rather than complexity, and unambiguous solutions rather than paradoxical ones.

It is reasonable to assume that these changes within the higher educational institutions, along with changes in the relationship between the government and the higher educational institutions, has led to changes in the roles of the leaders within the institutions, both referring to what kind of tasks leaders are supposed to solve and which responsibility and authority they have.

Decentralization and delegation of responsibility from public authorities to higher education institutions, and from institutions to faculties and basic unites are important elements in this development. However placing new responsibilities on lower levels in the education system increases the pressure on the academic leaders on these levels (Aasen \& Stensaker, 2007).

In short, it would be interesting to see how the role of deans has been influenced by these developments, and how the deans experience the changes of role.

\section{Theories of Leadership and Management}

In research literature there are mainly two different views 
on leadership: Leadership could be conceived as the individualistic qualities of a person or as organizational function as a response to external or internal challenges within particular frameworks of history and social structure.

The idea that leadership is based on individual attributes is known as trait theory and goes back to antiquity when Plato in The Republic and Plutarch in his Lives discussed the attributes of leaders. The main question for this sort of theory is "What qualities distinguish an individual as a leader?" In this theory leaders are mainly individuals who are born leaders or develop leader qualities in early childhood. According to these theories a good leader can lead anything. To educate leaders seems a bit paradoxical from this perspective.

Later leadership theories see leadership more as a relation between an individual or group of individuals and their surroundings. There is often a distinction between contingency theories and functional theories. Situation, context and function are central concepts in these sorts of theories. According to these theories leadership can be learned and developed, but a good leader in one context is not necessarily a good leader in another. The focus is on explaining leadership behaviour.

What leaders actually do is to a large degree dependent upon characteristics of the situation in which they function. Leadership is a complex process consumed by complications of timing, circumstances and individuals. Thus, a simple formula for leadership does not and will probably never exist.

The time spectrum shows a theoretical evolution that advanced from trait theories to behavioural theories, followed by contingency theories to transformation and transactional theories. Today we will often find a mixture of these theories when leaders and leadership are discussed (Aasen \& Stensaker, 2007, Bargh et al, 2000).

It has been fashionable to distinguish leaders from managers. It can be said that one does the right things; the other does the things right (Zaleznik 2004). There is little disagreement that leadership is a process for influencing decisions and guiding people, whereas management involves the implementation and administration of institutional decisions and policies. Management is a relatively structured process for achieving organizational objectives. Leadership is more often viewed as an interpersonal process for establishing objectives, inspiring and motivating followers. However, a meaningful understanding of both concepts can only be reached when they are examined in relation to one another. Management reacts, while leadership transforms (Neumann \& Neumann, 2000, Taylor \&Machado, 2006).

The manager can never be free to forget the work; can never have the pleasure knowing, even temporarily, that there is nothing left to do (Mintzberg, 2009). The pressures of the managerial environment do not encourage the development of reflective planners. The manager does not leave the telephone, the meeting, or the e-mail to get back to work. These contacts are their work. On the other side, according to Waldrop the adaptive institution must live on the edge of chaos. This creates a delicate balance between stability and instability that must be orchestrated by strong leadership (Waldrop, 1993).

According to Henry Mintzberg it is agreed that managing is controlling and doing and dealing and thinking and leading and deciding and more, not added up but blended together. Leaders cannot simply delegate management; instead of distinguishing managers from leaders, we should be seeing managers as leaders, and leadership as management practiced well. Leadership is earned, not anointed. Leadership and management is neither a science nor a profession; it is practice, learned primarily through experience, and rooted in context.

To him managing is about a person performing on three levels, from conceptual to concrete: with information, through people and to direct action.

Managing through information: monitoring (reaching out for useful information), disseminating (sharing inside), and acting as spokesman (outside). The job of managing is significantly one of information processing, especially through a great deal of listening, seeing and feeling, as well as a good deal of talking. One direct use of information is to control, that is, to direct the behaviour of "subordinates". The trick is not to avoid the controlling role but to avoid being captured by it - which is true for all the roles of managing. Controlling through decision making, designing (structures and strategies), delegating, designating (authorizing for doing choices), distributing (allocating resources), deeming (imposing targets and expecting performance according to them - some deeming is fine, managing by deeming is not)

Managing by people: To manage with people instead of through information, is to move one step closer to action but still remain removed from it. Leadership can certainly make a difference but leadership is earned as well as learned, not granted. The job is to energize people (in the leading role, managers help to bring out the energy that exists naturally within people) developing people (managers helping people to develop themselves), building and maintaining teams (not only bonding, but resolving conflicts within and between groups), establishing and strengthening culture (through the institutional embodiment of purpose and infusion with value, also called strategy). Nothing legitimates and substantiates the position of leaders more than their ability to handle external relations. Above all else, leaders control a boundary or interface. This is done by networking, representing, conveying and convincing, transmitting and buffering. Managing on the edges - the boundaries between the unit and its context - is a tricky business.

Managing action directly: Doing on the inside (managing projects proactively and handling disturbance reactively), dealing on the outside (building coalitions and mobilizing support). Too much leading can result in a job free of content - aimless, frameless and actionless - while too much linking produces a job detached from its internal roots - it produces public relations instead of tangible connections. 
The manager who only communicates never gets anything done, while the manager who only "does" ends up doing it all alone. The manager who only controls risks controlling an empty shell of "yes" men and women. Therefore a manager has to practice a well-rounded job.

The pressures of the managerial environment do not encourage the development of reflective planners. The manager does not leave the telephone, the meeting, or the e-mail to get back to work. These contacts are their work. On the other side, according to Waldrop the adaptive institution must live on the edge of chaos. This creates a delicate balance between stability and instability that must be orchestrated by strong leadership (Waldrop, 1993).

Management and leadership are as much about lateral relationships among colleagues and associates as it is about hierarchical relationships. A good part of the work involves doing what specialists do, but in particular ways that make use of the manager's special contacts, status and information. The leader has to help bringing out the best in other people, so they can know better, decide better and act better.

Strategic planning can play a role such as providing analysis to managers, helping translate intended strategies into realized ones, and providing a control device, but that is not necessarily effective for the development of strategy. One can view strategic management from positive as well as negative perspectives. It serves as a mechanism to provide direction to an institution and at the same time it has the potential to propel the institution on a perilous course (Mintzberg, 1994, Mintzberg et al 1998).

The role of deans implies both leadership and management; however, the focus has changed from leadership to management during the last years.

\section{Deanship and Academic Leadership}

There is no such thing as a standardized dean. The concept dean is used differently in countries throughout the world and even varies between institutions in the same country. However an academic dean is a leader and manager of an organizational entity in higher education institutions.

Leadership in such institutions has changed over time. Historically the role of academic deans emerged when presidents or rectors needed an individual to relieve them of duties. The dean's primary role was to maintain collegiate and human values in an atmosphere of increasing scholarship and specialization. The typical dean was the elected professor. Today deans are more often appointed, externally recruited or even hired for fixed periods than elected (Rudolph, 1990, Gould, 1964). The responsibility of deans can be categorized in areas:

- Professional and strategic responsibility. Deans have superior professional and strategic responsibility; it includes responsibility for developing goals and strategies for education, research and communication, and responsibility for quality control and development.
- Economic and administrative responsibility. This includes budgeting, fundraising, controlling income, spending and managing resources according to laws and regulations.

- Personnel responsibility. This includes human resource management and development. The dean has to see to that the unit has the right human resources and competences to meet the demands and strategic goals. The dean should also prepare for good work conditions and is responsible for managing human resources according to law and regulations.

- Internal and external cooperation. Deans should attend to the interest of their units and stimulate for internal cooperation included cooperation with students and other departments. Deans should develop a good organizational culture, and represent their units in relation to private sector, public sector and general public. In addition they are responsible for international relations. Last but not least the deans are members of the leader team.

While the deans may still have kept some of the humanist ideals of the past, the academic dean of today is viewed quite differently. The deans' duties have changed from being almost exclusively staff, student and curricula oriented to include a multifaceted array of activities, such as budgeting and fundraising, personnel and environment management, program oversight and external public relations. As a result of legal and organizational changes, their positions got "enriched" with administrative duties while, at the same time, the former idea of a dean representing the academic staff on a collegial basis has declined more and more. The collegial role is crumbling while the managerial role takes over. Moving from an elected dean with collegial expectancies and academic internal standards to an employed dean representing the employer with managerial role expectancies and external defined standards implies challenges and conflicts. These areas of responsibility can be illustrated by differentiating the leader role. In his work Henry Mintzberg (1980) distinguishes between three basic types of leader/manager activities represented by 10 observable partial roles.

Deans need to offer service, be accountable, fulfil a moral role, act as a steward, build diverse communities with trust and collaboration and promote excellence. Expertise with budgetary matters is extremely important and experience in administration and supervisory skills are essential since deans are the individuals that hire and evaluate the academic staff (Wolverton et al, 2001, Robillard 2000, DiFronzo N, 2002).

Within this framework the tasks of deans can be interpreted as being that of functional leaders. Their role provides them with executive powers to manage personnel as well as material resources, and their strategic competencies can be seen as the formal equivalent to developing solutions to problems. Therefore deans have to assume managerial and 
entrepreneurial tasks; on the other hand they must be careful not to violate the academic values which connect them with their peers. Goal setting is the main task of a functional leader. Acceptance of goal is central to goal attainment. Only when goal acceptance is high is the energy to reach goal activated. Anyway with respect to goal setting theory, acceptance of goals by those who will have to act up to them is crucial for successful implementation of change (Locke \& Latham 2002, 2006).

One of the most demanding aspects of academic leadership in the current climate is the ability to respond productively to the myriad ongoing changes that characterize modern universities. However, deans cannot know everything. Some of the best skills a dean can possess are the constant thirst for knowledge, commitment to lifelong learning, and the courage to embrace the ever-evolving world of higher education. Along with exercising the necessary skills to meet the challenges of the position, the dean of an institution must always assume a leadership position. The dean needs always to be thinking ahead to the future while dealing with the present. Efficient and knowledgeable management is of considerable importance to any departmental entity, but under effective leadership much of it should be delegated to well-informed non-academic administrators.

D.G.Jones (2011) argues that the role of academic leaders is a role of crucial importance within the maelstrom that is today's academic environment. This argument holds regardless of the administrative structure found within any particular institution and regardless of whether the model of operation is a chair model or a faculty-college model. Heads of academic units are academic leaders whatever level they are occupying within the academic hierarchy, and regardless of whether they are appointed from inside or outside the university, until retirement or on a rotational basis for a defined period of time.

In the institutions of higher education, deans provide the delicate but crucial backbone of university decision making. They link central administration with academic departments. On the one hand, they serve as extensions of the presidency; on the other, they are regarded as extensions of the academic staff. Deans walk a delicate administrative tightrope. They head professional bureaucracies within professional bureaucracies. As deans within a university, they have legitimate authority, but within their faculty such direct power can rarely be exercised. Here, the dean often functions as a disciplinary expert, who happens to be carrying out administrative tasks. (Wolverton et al. 1999).

Deans are caught between the expectations of their colleagues and those of the central administration. Each group, because its success depends on the dean's performance, develops beliefs about what deans should and should not do. These expectations shape perceptions and understandings of the roles in which deans engage. In other words, the role of dean, and how it gets enacted, is influenced by social norms, by the perceptions of those who interact with deans, and by personal abilities. Through such interactions, deans create meaning that determines their behaviour in given situations. As administrators in hierarchical settings, deans behave in ways that seems situational appropriate to them, given the demands and expectations of those with whom they work.

When expectations of the university run counter to those of the academic staff, or when expectations of either entity remain ill defined, deans who attempt to meet these expectations experience a certain amount of conflict.

One function of good academic leadership is to make staff aware of the consequences of government policy for the university sector as a whole and their own university and faculty in particular. In order to do this the deans must have an understanding of the wider environment within which they are all functioning, and the implications of this for faculty dynamics. Time spent on jobs outside academia can have a positive effect on a dean accepting the strategic goals set by others.

\section{Methodology}

The empirical analysis is based on three main sources:

1. A review of articles and reports. This usually implies selection problems. However, since my study is concentrated on Norway and Scandinavia from resent years, there is not much to select from. The material is therefore more or less representative.

2. My personal experiences. Taken isolated the main methodological problem with those data is reliability. However those data are compared with other sources.

3. Survey data. The problem here is low response rate. Isolated these data are not valid, but seen in connection with the other sources they give an important insight.

\section{Empirical Material}

\section{Review of research studies}

In a study at Lund University (2009) most deans find that their tasks were adequate and sufficiently clear defined, but that frequent organizational changes kept creating uncertainties. Many deans argued that it was important that the dean had the possibility to participate in core activities such as teaching and research.

Many deans found that introduction of ICT (administrative systems) reduced their role as leaders and that they more and more were serving electronically based systems. In their opinion deans were at risk of being so event-driven that it was no longer room for strategic work.

Some deans were sceptical to big leader-teams. Their argument was that the bigger teams the more likely it was that they were reduced to alibies for already made decisions. Some deans stated that they experienced conflict in their roles between expectations from board and rectorate on one 
side and colleagues on the other.

The majority of deans had the opinion that research activities do not create good leaders and that it is a lack of rewards and incentives for leaders in higher education. However for most the greatest problem was lack of adequate administrative support.

In a study from Norway (Aasen \& Stensaker 2007) found that academic leaders participating in leadership training program was generally positive. However, this seems not to indicate a managerial view of leadership. One of the most profound effects of leadership training program was that the participants had established a stronger identity as a "leader". Participant's definition of leadership after completion of the program was one that was closely associated with developing visions and strategies for the organization. Academic merits were still viewed as important, but not as a sufficient foundation for forward-looking institutional leadership.

Stress and lack of time was the dominant factor limiting participants' ability to implement what they learned at the program. It was a mismatch between leadership expectations and organizational characteristics. The rather high expectations some of the leaders had after completion of the program seemed to have been quite rapidly brought down to ground when facing the organization afterwards. As such one could question the relevance of only training leaders when seeking to establish a more dynamic organization.

In a study from 2008 Arntzen \& Aastveit found surprisingly big differences in how the deans experience the distribution of tasks connected to their roles. It seems to be a general tendency to value the role as "figurehead" and external relations together with dealing with transfer of information as being of less importance and extent than other tasks.

According to the study these differences could be explained in different ways. There might be genuine differences in tasks based on institutional or faculty situation. The differences might also be due to individual choices based on interest or competence or be a result of how leaders want to spend their time, more than how they actually act.

Two quite sustainable different types of leaders were identified one more managerial type of leader and the other a more entrepreneurial type of leader. The managerial type of leader focused mostly on managing personnel and conflict solving, while the entrepreneurial type of leader focused mostly on strategy, innovation and research.

On the positive side most of the respondents emphasized their opportunity to have real influence on the development of teacher education and considerable freedom to shape their own role as dean. Some of the respondents connected this to development of unitary leadership. In addition most respondents emphasized the importance of working with professional, positive and resourceful colleagues.

On the negative side the respondents most often mentioned high work load and stress often caused by lack of capacity and competence in administrative support. Problems were also connected to the fact that support and administrative systems were not adjusted according to development from divided to unitary leadership.

The most important measures suggested on national level were more explicit non contradictory priorities. An offer of formal managerial education or managerial development for leaders was also asked for. On the institutional level many mentioned the unreasonable budget model with lack of legitimacy which results in unpredictable outcomes and eternal fights for resources. Better administrative support and offering of managerial development was also mentioned frequently. On faculty level suggested measures were better and more extensive administrative support.

It seems that deans from university colleges and deans from universities had different preferences. Deans from universities were stressing formal education somewhat more often than deans from university colleges. When it came to what qualifications were most important for a leader of teacher education, it looks as if the answers are divided in two groups. On the one side were those who think experiences from school and teacher education were of crucial importance, on the other side were those who emphasise academic competence, preferably at $\mathrm{PhD}$-level, as the most important.

Several respondents stressed experience as leader, and some that this experience has to be extensive since the job was very demanding. When it comes to personal characteristics there were no agreement, but decisiveness and ability to communicate and cooperate were mention most frequently.

\section{Personal experiences}

When I was a student and later on lecturer at the university, the dean was a distinguished, elected professor. Deanship was taken on by turns between institutes of the faculty. Deanship was looked upon as a necessary burden by most of the professors even though most administration and managerial work was done on the institutional level.

When I started as a dean I had many years of experience as leader from both private enterprises and public services, first of all in the health sector. I was for the first time in the history of the University College an appointed, externally recruited dean at the faculty of teacher education. I was employed by the board with rector and the university college director as my prime superiorities, which sometimes was a bit confusing since the division of responsibility between them was not always clear. On the campus level my most significant relation was to the head of campus administration. At the faculty level my most significant relations were the board elected by the academic staff, later on also with external representatives from schools and pre-schools, and my heads of studies. Other important role partners were representatives of local unions and student association. However the relation to the academic collegium was in my opinion the most important, without their acceptance that means without legitimacy, I would not had accomplished much.

As a dean I was member of the institutional leader team, composed of the deans and led by rector. This team was 
meant to deal with strategic questions, which it sometimes did, but it also had to deal with a lot of day to day operational questions.

I came to a faculty that up to my arrival had had divided leadership with an elected dean and an externally recruited, appointed office manager. The faculty had its own administration lead by the office manager who was responsible to the administrative director. This was changed to a unified leadership. The main argument was to strengthen the academic leadership. However, the result was that the role of the dean was "enriched" with managerial and administrative tasks in a way that left less and less room for academic leadership.

Simultaneously, for the first time the institution had an appointed rector but still a divided leadership on top level. New public management was introduced with considerable force. During my time as a dean, I had three rectors of which two were elected, and three different directors.

The University College had three campuses when I started as dean. Soon a process started to reduce the number of campuses from three to two. At the same time my office manager retired and local administrations were shut down and a new common administration established directly under the University College director. It did not work too well, and after a short period we ended up with a campus-based administrations led by a leader team composed of the campus deans and head of campus administration. In addition we had a central administration taking care of institutional matters.

Then started a process for merging three University Colleges which included a discussion of changing from enterprise organized activities to discipline organized. The process failed with the consequence of a new rector taking over and the start of a strategy process for a new, independent University College.

Through all these changes the organizing of teacher education was changed, with new studies, new curricula and new qualification requirements. Teacher education moved from a mainly experience based education to a mainly research based activity and the faculty started preparing for teacher education as a Master's degree programme instead of a four year Bachelor's degree programme. This meant new demands for qualification and new standards for recruitment. Personal management, specially recruitment and competence development, moved to be a dominant task. The change from a staff dominated by lecturers to a staff where more than $50 \%$ had their $\mathrm{PhD}$ and where a group of professors was established also changed the prerequisite for academic leadership.

The position of the dean was not remarkably changed during these processes. The dean was head of the teacher education faculty and member of the leader team all the time. The most significant relations, with rector, director and board were unchanged even though the persons changed. However the organizational changes were a challenge since the majority of the staff disagreed with the institutional leadership on the strategy for the University College. Due to externally introduced new goals for the teacher education conflict between traditional, collegial leader role and managerial leader role was increased and need for motivation and conflict solving developed fast.

The distribution and content of tasks changed considerably during these processes. First of all the institutional strategic processes were time-consuming at the expense of teacher education centred processes. Secondly the amount of administrative work increased dramatically due to changes in the administrative support and introduction of new public management.

My experience was that not two weeks were similar even though the general tasks were more or less the same. Mintzberg (2009) estimated that on average a manager is occupied about $50 \%$ of his or her time in meetings. By selecting three weeks at random I found that about $30 \%$ of my time was spend in external meetings with three or more persons, about $15 \%$ in internal meetings outside my faculty and about the same amount in internal meetings at the faculty. In addition at least one hour each day was spend on reading and managing e-mails or other ICT based systems. Together these activities constituted about $80 \%$ of my ordinary working time. There was no room for teaching or research activities and few possibilities for career improvement. However I had the opportunity to participate in a leadership training program for deans.

\section{Result of questionnaire send to deans of teacher education}

A questionnaire was send to more than 20 deans responsible for teacher education in Norway. This text is based on answers from 8 of them. Even though this is a selected sample with the possibility of bias, I think the answers confirm other results and are quite illustrative for the actual situation.

All deans was appointed and externally recruited even though a couple had been elected deans earlier. All have experiences from leading positions in higher education either from higher education institutions or governmental bodies. The answer on who were their three most important role partners as deans, 6 answered the institutional leaders, their own leader team and their staff or representatives of the staff, only one mention representatives from school sector and one mention representatives for the owner (Government).

Three out of eight experience no or little role conflict, the rest experience conflict between representing their faculty and representing the whole institution or between expectancies from their staff and expectancies from their superiors.

Six out of eight thought development of strategies and plans were the most important task while one thought implementation of other's strategies and plans were most important, and one that managing personnel was the most important. Six out of eight thought it was a good correspondence between what they thought most important and what task was most time consuming.

On the question: How do you experience to be part of a 
rapidly changing system influenced by international and national trends? Six out of eight deans answer that they found it both frustrating and problematic with low predictability and frequent changes, but they also saw the potential for change and development as positive, or as one formulated it:

"It is frustrating because it would have been possible to create better educations if the institution had more predictability and greater freedom. On the other side the ever changing environment creates possibilities for development and change."

One dean found it only challenging and positive, while another found it only frustrating and negative.

On the question: In your opinion what is the most attractive about being a dean? Seven out of eight answer that the most attractive about their job was the possibility to influence something that they found important, or as one formulated it:

"The teacher profession is the most important profession in the world. To be able to manage and influence the development of teacher education is most rewarding."

On the question: If you were asked to suggest one initiative which could make the job as a dean more attractive, what would you suggest? Four out of eight mention more and better administrative support. Two deans mention better and more predictable institutional leadership and one mentions more influence on the strategic development of his institution.

\section{Discussion}

Higher education institutions are organized in different ways. Even though every institution is different in some details there are two main models which I would call the university college model and the university model. In the university college model the academic staff is organized in entities according to the profession they educate. These entities, called faculties or departments, have usually a unified leadership, and are led by a dean. Members of the staff represent different academic disciplines and can be organized in more or less formal groupings due to discipline. In the university model the academic staff is organized in institutes according to academic discipline. A number of institutes constitute a faculty led by a dean. In this model, economic and personnel responsibility is often delegated to the institutional level and responsibility for education of a profession i.e. teachers is often delegated to a program coordinator who is responsible for ordering relevant resources from different institutes. All together we may conclude that dean's position and thereby role, differs dependent on organizational model. However, all deans are mid-level managers.

In a (surprisingly) short period of time the role of deans in higher education has changed from the elected, distinguished professor to an externally recruited manager. For a substantial part this change has been justified by arguments of quality and intent of strengthening the academic leadership. This change is concurrent with the introduction of new public management as a managing system. It indicates that the role of deans as an academic leader has been impaired at the expense of administrative and managerial tasks.

A dean has a crucial role linking central administration to academic activities in higher education institutions. If it is thru as argued in this article, that it is not possible to be a good leader, at least over time, without taking care of managerial tasks, and that good management is dependent of the legitimacy of leadership, then this change is not without challenges.

Even though the role as leader and manager is intertwined it is also a source of conflict. Many deans experience conflict between being a manager implementing and administrating institutional and governmental decisions and policies, and being a leader with the possibility to influence the development of academic activities. This is in their opinion, partly due to inconsistent and ever changing framework conditions and indications. To do well the deans have to have the opportunity to balance this conflict. However, the conflict is not necessarily something to avoid. Some deans think of conflicts as a source of creativity.

It is expected that deans are able to cope with all sort of managerial tasks including priorities, delegating and solving them within a limited space of time. Most deans think developing strategies and plans are the most important task, but how they allocate time and resources to tasks differ.

Most deans like and are enthusiastic about their job. The different sources of data seem to agree that it is important to deans to be able to influence the development of the education they are responsible for in a personal way. They like to think that their efforts "make a difference". However, many deans feel their positions threaten by increased managerial and administrative tasks.

Most deans find their job rewarding because they are able to influence the development of teacher education which they find most important. However, there is not possible anymore to combine the dean's role with academic activities as teaching and research, and experiences in teaching and research is not necessarily important for doing a deans job. Being a dean gives little credit to an academic career.

The changes in the role of deans probably means a professionalization of academic leadership which imply changes of criteria for recruitment, more and better supplementary education, and change of incentives. As the role of deans is being more and more management oriented it will probably require that moral and social incentives are compensated with economic incentives. However, the main incentive for doing good cognitive work are the feeling of autonomy, mastery and of making a contribution, or as Daniel Pink (2009) formulates it:

Perhaps it's time to toss the very word 'management' into the linguistic ash heap alongside 'icebox' and 'horseless carriage'. This era doesn't call for better management. It calls for a renaissance of self-direction.....In our offices and 
our classrooms we have too much compliance and way too little engagement.... It's in our nature to seek purpose...

Even though incentives can be substituted, research seems to indicate that economic incentives cannot substitute moral and social incentives for this kind of work (Pink 2011). Therefore, the development presented here give reason to be worried about the future role of deans and deans' work.

\section{REFERENCES}

[1] Aasen, P. \& Stensaker, B. (2007) Balancing trust and technocracy? Leadership training in Higher education. International Journal of Educational Management 21 (5) (371-83)

[2] Arntzen, E. \& Åstveidt, K. (2008) The deans in Norwegian Teacher Education Paper at ATEE Annual Conference 2008, NRLU rapport 2008

[3] Askling, B. \& Stensaker, B.(2002) Academic leadership: Prescriptions, practices and paradoxes. Tertiary Education and Management 8 (2), (113-125)

[4] Bargh, C., Bocock, J., Scott, P., \& Smith, D. (2000) University leadership: The role of the Chief Executive SHRE/Open University Press, Buckingham

[5] DiFronzo, C. N. (2002) The academic dean Widener University. Retrieved from www.newfoundations.com/Org/Theory/DiFronzo721b.html

[6] Gould, J. W. (1964) The academic deanship. New York: Teachers College Press.

[7] Jones, G. D. (2011) Academic Leadership and Departmental Headship in Turbulent Times. Tertiary Education and Management 17 (4), (279-88)

[8] Lock, E. A. \& Latham, G.P. (2002) Building a practically useful theory of goal setting and task motivation. A 35-year odyssey. American Psychology 57 (9)
[9] Lock, E. A. \& Latham, G.P. (2006), New directions in goal-setting theory. Current Directions in Psychological Science 15 (5).

[10] Lund Universitet (2009) Granskning av dekanrollen.

[11] Pink, D. (2009) Drive. The surprising truth about what motivates us. New York: Riverhead Hardcover

[12] Mintzberg, H. (1980) The nature of managerial work. Englewood Cliffs: Prentice Hall

[13] Mintzberg, H. (1994) The Rise and Fall of Strategic Planning, Plans, Planners. N.Y.: Free Press

[14] Mintzberg, H. (1998) Covert Leadership: Notes on Managing Professionals, Harvard Business Review 76 (6), (140-47)

[15] Mintzberg, H. (2009) Managing, Prentice Hall

[16] Neumann, Y., \& Neumann, E. (2000) The President and the college bottom line: the role of strategic leadership styles. Library Consortium Management 2, (97-112)

[17] Robillard, D (2000) Toward a definition of deaning. In Robillard, D. (Ed.). New directions for Community Colleges, San Francisco, CA : Jossey Bass

[18] Rudoph, F. (1990) The American college and university. A history. Athens. GA: University of Athens Press

[19] Taylor, J., \& Machado, M. (2006) Higher education leadership and management: From conflict to interdependence through strategic planning. Tertiary Education and Management 12 $(137-60)$

[20] Waldrop, M. (1993) Complexity: The Emerging Science at the Edge of Order and Chaos N.Y: Simon and Schuster

[21] Wolverton, M., Wolverton, M.L., \& Gmelch, W.H. (1999) The Impact of Role Conflict and Ambiguity on Academic Deans; Journal of Higher Education 70

[22] Wolverton, M., Gmelch, W., Montez, J \& Nies, C. (2001) The changing nature of the academic deanship Vol. 28, no. 21. San Fransico, CA.: Jossey Bass

[23] Zaleznik, A. (2004). Managers and leaders. Are they different? Harvard Business Review 82 (6) 